Neste artigo pretende-se mostrar como a história enquanto memória inventada influi na constituição do estilo de aprendizagem. Os parâmetros utilizados pelos pais e professores para explicar as dificuldades dos filhos/alunos, têm sido influenciados pelo modo como associam as dificuldades de seus filhos à sua própria experiência e pelo discurso cientificista. A mudança do rumo histórico será possível a partir da mudança do discurso no qual está imerso o sujeito da aprendizagem.

Estilo de aprendizagem; memória inventada; história; discurso; mudança de rumo

THE PARTICIPATION OF THE HISTORY IN THE CONSTITUTION OF THE STYLE OF LEARNING

The article focuses how the history while invented memory, influence in the constitution of the style of learning. The parameter used by parents and teachers to explain the difficulties of children/students, are influenced by the way how they relate the difficulties of their children to their own experiences and by the scientificist spcech. The change of the bistory course will be possible from the change of speech in whish are immersed the subjet of learning while a student.

Learning style; invented memory; history; discourse; course change

\section{A PRESENÇA DA HISTÓRIA NA CONSTRUÇÃO DO ESTILO DE APRENDIZAGEM}

A Família e a Escola como instituições preocupadas com a aprendizagem informal e formal nem sempre estão atentas ao "estilo de aprendizagem" do filho/aluno. O que mais chama a atenção dos pais e dos mestres é a resposta objetiva do aluno frente às diferentes solicitações pedagógicas. O estilo de aprendizagem é entendido como uma forma singular e própria de lidar com o conhecimento e com o saber, que expressa o modo como se lida com a vida. Se viver e aprender são faces de uma mesma moeda, é fundamental compreender o estilo de aprendizagem na sua gênese.

Considerar o estilo de aprendizagem poderá abrir um espaço para acolher e compreender os diferentes modos de aprender, sem considerá-los necessariamente manifestação de patologia da aprendizagem.

Kupfer (1999, p. 65) coloca a questão: "Problemas de aprendizagem ou estilos cognitivos". Propomos considerar a cognição como faculdade que

Pedagoga, Psicopedagoga, Mestre em Psicologia da Educação pela Universidade São Marcos, São Paulo - SP. Conselheira da Associação Brasileira de Psicopedagogia. 
permite a aquisição de um conhecimento, a partir do estilo de aprendizagem. É a partir do estilo que o sujeito da aprendizagem transforma o conhecimento em saber ao lhe atribuir seus significados. Sem esse movimento de transformação do conhecimento em saber por um processo de singularização, não há apropriação do conhecimento pelo sujeito da aprendizagem. Seja na educação informal, fora da escola, como na formal, um sujeito da aprendizagem conhece, transforma e se apropria do conhecimento, dandolhe uma característica própria, permeada por seu estilo de viver. $\mathrm{O}$ conhecimento se transforma em saber quando o sujeito dele se apropria.

Como psicopedagoga, ao optar por um modelo de intervenção psicopedagógica dinâmica, na qual está implícita a consideração da subjetividade na constituição do sujeito da aprendizagem, parto do princípio de que é fundamental levar em consideração a bistória de vida, não como conjunto de fatos objetivos, mas como representação simbólica das experiências que marcaram o aluno e, sobretudo, marcaram os pais dos alunos.

Para compreender a queixa escolar a partir do estilo de aprendizagem, é preciso ir à gênese do estilo e à história de vida como "memória inventada". Esse termo é utilizado por Manoel de Barros (2003) como título da obra que retrata suas lembranças sobre a infância, como memória inventada, ou seja, ressignificada.

A história de vida pode, em parte, explicar a relação do sujeito da aprendizagem com o conhecimento e com o saber, isto é, com seu estilo de aprendizagem. Os adultos significativos transmitem no plano inconsciente essa memória. A bistória de vida, como memória inventada influi em parte no estilo de aprendizagem e poderá nos fornecer algumas pistas a respeito de sua constituição psíquica.

Para compreender a dificuldade de aprendizagem e desenvolver um processo de intervenção, não é suficiente conhecer apenas questões objetivas sobre a dificuldade de aprendizagem, esses são os fatos. O psicopedagogo, tal qual o detetive num romance policial, busca pistas para compreendê-los. Os fatos precisam ser relacionados a essa história. "No romance policial, o que emociona o leitor não é somente a história do crime, mas toda a investigação que levou à revelação do crime.” (Rubinstein, 2003, p. 159)

Ao considerar a subjetividade, podemos não somente compreender dinamicamente a queixa escolar, mas efetivamente desencadear possibilidades de alguma mudança de posição do sujeito diante do saber e do conhecer, que poderão reverter indiretamente nos fatos. Ao poder viver uma nova experiência de aprendizagem, sob a perspectiva de um outro que lhe atribui outro olhar, há alguma possibilidade para mudanças de diferentes ordens. 
O sujeito da aprendizagem, interpelado sobre sua relação simbólica com o objeto do conhecimento, poderá, se o desejar, mudar. Aprender significa relacionar-se com o conhecimento e sobretudo apropriar-se dele, a partir das possíveis novas ressignificações de cada sujeito da aprendizagem.

A investigação sobre o estilo de aprendizagem começa nas entrevistas iniciais, a partir dos relatos dos pais, quando apresentam suas versões sobre a queixa escolar e as dificuldades do filho. Nessa ocasião, estão presentes suas próprias lembranças e memórias sobre as experiências com seus pais e familiares (irmãos, tios etc). Muitas vezes, os pais temem que a história do seu possível fracasso se repita. Não é incomum que, ao presenciarem alguma dificuldade no filho, mesmo que seja pertinente ao processo, facilmente fiquem alarmados.

Pais costumam ter expectativas em relação aos filhos; o mesmo podemos dizer em relação aos mestres. Quando por alguma razão o filho/aluno não corresponde às expectativas, no imaginário dos adultos significativos vêm à tona as marcas de suas próprias vivências como sujeitos da aprendizagem. Não é incomum ouvir o seguinte depoimento: "fui um mau aluno, tal como minha mãe; tinha certeza de que minha filha seria igual a mim e à minha mãe".

A expectativa em relação ao outro é constitutiva. Sem ela, o bebê humano não se constitui. Mas é preciso um longo e complexo caminho para que o aluno consiga desvencilhar-se dos fantasmas que povoam o imaginário dos pais e de seus mestres. Como afirma Dolto (Mannoni, 1981, p. 12) na introdução ao livro $A$ primeira entrevista em psicanálise:

"O que este livro também ensina é a descoberta, que para muitos leitores será nova, de que, durante uma única entrevista psicanalítica, já aparece claramente a intricação das forças inconscientes entre genitores, ascendentes e descendentes. O leitor compreenderá sem dificuldades como um ser humano, desde a sua vida prénatal, já está marcado pela maneira como é esperado, pelo que representa em seguida, pela sua existência real diante das projeções inconscientes dos pais..."

As expectativas dos adultos estão permeadas pelas suas próprias experiências, que, de forma inconsciente, vão sendo reatualizadas na medida em que esses adultos reconhecem nos filhos e nos alunos algo que em sua memória está presente e os ameaça constantemente. Não são os fatos em si mesmos que povoam o imaginário, mas é o valor simbólico que a eles cada qual atribui.

Pais temem que suas próprias histórias ou de seus familiares próximos se repitam nos filhos. "Os pais comeram uvas verdes e 
por isso os filhos ficam com os dentes embotados." Essa afirmação usada por Dolto (1981, p. 24) na obra citada e originariamente pertencente ao texto bíblico dos Profetas (Jeremias, capítulo 31 vers. 29), servirá para ilustrar a importância das experiências de aprendizagem que os adultos significativos tiveram em sua própria infância, as quais são transmitidas pelas gerações.

$\mathrm{Na}$ Bíblia, essa afirmação vem seguida do seguinte versículo: "cada um morrerá por sua própria falta. Todo homem que tenha comido uvas verdes terá seus dentes embotados", significando que cada qual é responsável por si mesmo. Por que será que Dolto a utiliza afirmativamente, desconsiderando o versículo seguinte? Como ela mesmo comenta, a frase não é para culpar os pais, mas para afirmar que "os pais e os filhos de tenra idade são dinamicamente participantes, indissociados pelas suas ressonâncias libidinais inconscientes" (Dolto, 1981).

Por que isso ocorre? Talvez outro dito popular possa explicar isso em parte: "O fruto nunca cai muito longe da árvore", ou seja, o processo de identificação, presente na constituição psíquica do sujeito da aprendizagem favorece em parte essa possível repetição. Identificação não é o mesmo que mimetismo, cópia, mas de tomar para si traços de algo que já estava de alguma forma latente no imaginário. Não haverá por parte dos pais um esforço inconsciente para que o fruto não caia longe da árvore? Simultaneamente, podemos dizer que há também, por parte do filho, um movimento para a construção de uma pertença, a partir da identificação com certos traços de seus pais.

Em supervisões e assessorias a professores de Escola Pública, temos ouvido depoimentos a respeito de pais de alunos com fracasso escolar, que manifestam claramente seu "orgulho" diante do sucesso profissional, apesar da falta de escolarização.

Numa pesquisa com famílias de escolares nos meios populares, Lahire, sociólogo, em sua obra Sucesso escolar nos meios populares (1997), relaciona o aproveitamento escolar com o capital cultural familiar que é transmitido, porém o relativiza, mostrando a pertinência de levar em conta as particularidades e singularidades. Ele exemplifica por situações nas quais, apesar de alguns pais não terem conseguido fazer uma adequada transmissão cultural, não houve impedimento para que seus filhos obtivessem sucesso escolar.

$\mathrm{Na}$ intervenção psicopedagógica dinâmica pretende-se desencadear processos de mudanças, mas é o sujeito mesmo que, ao mudar de posição frente ao objeto, consegue aprender. O psicopedagogo, como mediador, tem a obrigação dos meios, conceito utilizado por Meirieu (2002). Esse autor se posiciona claramente sobre o que se deve esperar do educador: “... podese exigir dele que ponha em prática os meios mais diversificados e os mais inventivos possíveis para facilitar o êxito dos alunos, tanto em termos de inventividade didática, quanto de acompanhamento pedagógico..." (2002, p. 247).

Cabe-nos como psicopedagogos oferecer bons e pontuais recursos, porém estes não são garantia para 
que ocorram mudanças: é o sujeito que deve decidir-se pela sua mudança, e a nós cabe observar se os recursos oferecidos sensibilizam ou não o sujeito da aprendizagem, se ele fica tocado pela experiência. Sabemos $a$ posteriori dos seus efeitos. Aqui também está presente a história. Na psicopedagogia dinâmica, abandona-se a certeza da eficácia dos meios, dos métodos. É olhando para trás, que vamos reorganizando o presente, mas sem certezas.

Considerar essas questões ligadas à história de vida como memórias inventadas, na constituição do sujeito da aprendizagem permitirá perceber a queixa escolar a partir de outra perspectiva. A inclusão da história de vida na análise das dificuldades de aprendizagem permite compreender o presente, a partir do passado; não para explicações fechadas, mas para mostrar outras possibilidades no rumo pessoal do aprendiz.

Quando o historiador/psicopedagogo admite epistemologicamente o paradigma da incerteza defendido por Prigogine (Meirieu, 2002, p. 246) ele está identificado com uma ética educacional voltada para interrogações. Essa ética se contrapõe ao conceito de profecias auto-realizadoras (Watzlawick, 1994, p. 97) que estão presentes com bastante freqüência no imaginário de alguns progenitores e dos professores.

Não é fato incomum, na clínica dos problemas de aprendizagem, ouvir por parte dos pais um discurso permeado da certeza de que o fracasso escolar é uma "repetição de filme", uma repetição da forma como um dos pais ou ambos viveram a experiência escolar. Alguns deles chegam a falar de teorias implícitas, as quais são representações e generalizações construídas por cada um. Um exemplo é a seguinte afirmação: "quando os pais foram mal na escola, os filhos também irão mal". A finalidade da intervenção psicopedagógica é quebrar ou ressignificar algumas crenças implícitas que sustentam o estilo de aprendizagem. Para alguns pais, seu filho desde sempre foi agitado, ou desde sempre foi distraído, dependente etc.

Atualmente na escola há um novo discurso regendo a compreensão do fracasso escolar do aluno. Este novo discurso rege-se pela "patologização da aprendizagem”. Dito de outra forma: o aluno não aprende direito por "sofrer de doenças". Já na Educação Infantil, não é prática incomum alguns educadores - diante da resposta insatisfatória do aluno na alfabetização - preocuparem-se com a possibilidade de ele ser disléxico, solicitando uma avaliação clínica como medida preventiva. Na Educação Fundamental, não são raras as situações em que os educadores olham para a inquietude do aluno manifestada na falta de atenção e hiperatividade como uma patologia de natureza orgânica. A dificuldade do aluno para responder à expectativa do adulto significativo manifestada pelo desempenho inadequado deve ser pensada não somente nos aspectos biológicos e cognitivos.

Para que uma criança se interesse pelo conhecimento, é preciso que seja capturada pelo olhar do adulto que lhe mostra um objeto caro, valioso. Sem esta "sedução positiva", a 
criança é deixada de lado, não ouvida na sua angústia diante do novo que a vida lhe apresenta. A base para aprender é o afeto, ele sustentará o resto.

Segundo Pain (1985, p. 5), são as quatro estruturas: organismo, corpo, inteligência e desejo "que permitirão desde o nascimento - e através destas relações (afetivas de base) cumprir justamente o ciclo de apropriação do conhecimento.

O conceito das quatro estruturas proposto por Pain, favorece uma visão integrada do sujeito da aprendizagem. O que está presente hoje no discurso contemporâneo é uma visão parcial da compreensão do fracasso escolar. A pergunta que se faz para o fracasso na aprendizagem é única: "qual é o defeito orgânico do aluno que pode explicar suas dificuldades? $O$ discurso cientificista privilegia apenas a leitura da estrutura orgânica. A história se repete.

$\mathrm{Na}$ década de 70 , os educadores estavam compreendendo o fracasso escolar pelo viés neurológico da Disfunção Cerebral Mínima. Grupos de alunos da escola pública eram encaminhadas para diagnóstico neurológico. Hoje, o discurso mudou um pouco: busca-se possível explicação para a possível patologia da aprendizagem como efeito da falha nos neurotransmissores resultando em perdas nas funções executivas. Esse fenômeno explicaria a falta de atenção, a desorganização do aluno na relação com os seus materiais de estudo, a agitação corporal e o desinteresse.

Mas o sujeito da aprendizagem não é puro organismo. Quando se leva em consideração o todo, é possível considerar a influência da estrutura do desejo.

Paradoxalmente, pais e professores reconhecem o caráter seletivo da hiperatividade, reconhecendo que o filho e o aluno conseguem dedicar bastante tempo a atividades de que gosta. Apesar de reconhecerem as possibilidades de um vínculo adequado do filho e do aluno em outros discursos, por que esta visão reduzida? Não será devido à promessa de uma cura rápida através da medicação?

A mudança de comportamento e atitude diante da vida demanda experiência, dor, esforço, tempo. Não há certezas, quando se leva em conta a vulnerabilidade do ser humano. $\mathrm{Na}$ sociedade contemporânea, busca-se o efeito rápido de uma intervenção. É comum, diante de um aluno mal comportado, possivelmente mal educado, que alguns educadores interpretem seu comportamento como uma patologia.

A manchete da matéria sobre transtorno de aprendizagem "Ele faz. o que quer na sala de aula. Pode sofrer de déficit de atenção" (O Estado de São Paulo, 28/3/05) expressa também a força do discurso científico presente na mídia.

Uma das atribuições do psicopedagogo / historiador é justamente poder olhar para o sujeito da aprendizagem a partir de uma nova experiência vivida no presente, única, singular e, dessa forma, poder oferecer uma outra oportunidade para se reconhecer e possivelmente poder mudar o rumo histórico impregnado de possíveis traços dos adultos 
significativos presentes em sua memória inventada.

O estilo de aprendizagem é entendido como uma forma singular e própria de lidar com o conhecimento e com o saber. "O estilo é o Homem". Cada qual tem uma forma específica de lidar com a vida. Isso é o estilo. Cada qual tem um estilo para encarar os desafios e também para administrá-los. Para alguns, o estilo favorece e, para outros, o estilo é uma forma de impedimento.

O estilo - embora represente o sujeito tal qual o sintoma - diferencia-se dele, na medida em que não está cristalizado. Um estilo poderá ir mudando, a partir do desejo. Aprender e viver são o mesmo, ou seja, são duas faces de uma mesma moeda, no sentido de que a aprendizagem é análoga ao instinto do animal. Ao aprender, o sujeito da aprendizagem cria recursos para sua sobrevivência como humano. Às vezes um estilo de ser inquieto é interpretado como característica da hiperatividade ou do déficit de atenção. Com alguma freqüência observamos crianças agitadas que, pela força de sua capacidade criadora, são interpretadas como portadoras de distúrbios de aprendizagem. São sérias candidatas a se cristalizarem nessa concepção, até porque os pais dizem que ela puxon a um deles nessa agitação e que já estão prevendo seu fracasso escolar.

O medo pode imobilizar o pensar. Pais e mestres, temerosos diante do possível fracasso, estão imobilizados para pensar em outras alternativas. Provavelmente, diante de uma dificuldade da criança, os adultos significativos revivam, na sua memória, uma história inventada permeada de mitos de fantasmas. $\mathrm{O}$ real não existe, estamos constantemente reinventando a história, a partir de nossa memória, como diz Manoel de Barros: "tudo o que não invento é falso".

Quais são as atribuições do psicopedagogo que utiliza princípios da Psicanálise para intervir psicopedagogicamente, levando em conta o estilo de aprendizagem? Por ora destaco quatro atribuições, que expressam sinteticamente as idéias aqui pontuadas.

1. Colocar-se na posição de mediador que interpela o sujeito da aprendizagem para pensar em outra versão de História, descolada daquela familiar muito conhecida.

2. Ao fazer a leitura da produção do aluno, levar em consideração não apenas os fatos, mas os aspectos simbólicos presentes nas respostas às solicitações de diferentes ordens. Isso implica considerar simultaneamente a relação do sujeito da aprendizagem e a legalidade que rege o objeto do conhecimento. Deve-se perguntar, por exemplo, o porquê de a leitura compreensiva ocorre em determinados conteúdos e em outros não.

3. Junto à criança ele poderá ir sinalizando e dialogando a respeito desse estilo para que o aluno, ao tomar consciência dele, possa vivenciar sua singularidade não alienada no outro, que o vê como uma extensão sua.

4. $\mathrm{Na}$ escuta dos pais, ter como objetivo desencadear outras formas de pensar a dificuldade do filho, o que poderá contribuir, em parte, para que o aluno possa ser visto dentro da família na sua singularidade, para 
que ele não se contamine com os dentes embotados de seus pais.

Alguns pais pedem receitas diretas como, por exemplo, "Como fazer para abaixar a bola do filho?" Nesse pedido, está implícita a fantasia de que seria possível manipular a forma de ser do filho, a partir de uma boa prescrição.

Uma possibilidade para recolocar a questão aos pais poderia ser pela palavra justa que permita a construção de outras hipóteses para explicar o estilo de aprendizagem do filho, desvinculada da patologia. Manoni, citando Dolto, (1983, p. 30) propõe o que denomina de palavra justa para as possíveis sinalizações que os adultos significativos possam fazer para as crianças, com o objetivo de libertá-las do peso da fantasia que provoca sentimento de culpa.

Caberia também ao psicopedagogo, na escuta dos pais, oferecer a palavra justa, com o objetivo de usála como recurso para que eles possam desenvolver melhores condições para compreender com mais clareza os conflitos relativos à sua experiência como pais impregnados de suas memórias inventadas. No pedido de receitas, prescrições e modelos está implícita a falta de autorização para saber o que é bom para o seu filho. Há um esvaziamento do suposto saber dos pais.

A escuta psicopedagógica tem como meta recolocar os pais no lugar de suposto saber, bem como desencadear processos que possam de alguma forma aliviar a dor da culpa. Levar em consideração a história de vida como memória inventada para compreender o estilo do sujeito da aprendizagem, é mais um recurso para fazer a leitura da dificuldade de aprendizagem que, na perspectiva da psicopedagogia dinâmica, está sujeita a múltiplas e complexas variáveis. Nessa perspectiva, a análise da queixa escolar demandará um leitor disponível para aceitar a incerteza como norteadora de sua pesquisa.

\section{REFERÊNCIAS BIBLIOGRÁFICAS}

Barros, M. (2003). Memórias inventadas: a infãncia. São Paulo, SP: Planeta.

Dolto, F. In Mannoni, M. (1981). A primeira entrevista em Psicanálise. Rio de Janeiro, RJ: Campus.

Kupfer, M. C. (1999). Problemas de aprendizagem ou estilos cognitivos? In Psicopedagogia uma prática diferentes estilos. Rubinstein, E. (org.) São Paulo, SP: Casa do Psicólogo.

Lahire, B. (1997). Sucesso escolar nos meios populares. São Paulo, SP: Ática.

Mannoni, M. (1967). A criança, sua "doença e os outros". Rio de Janeiro, RJ: Zahar.

Meirieu, P. (2002). A pedagogia entre o dizer e o fazer. Porto Alegre, RS: Armed.

Rubinstein, E. (2003). O estilo de aprendizagem e a queixa escolar: entre o saber e o conbecer. São Paulo, SP: Casa do Psicólogo.

Watzlawick, P. (1994). Profecias que se autocumprem. Apud Watzlawick, P. (org.). $A$ realidade inventada. Campinas, SP: Editorial Psy II.
Recebido em março/2005. Aceito em abril/ 2005. 